BEZERRA NETO, F.; ROCHA, R.C.C.; NEGREIROS, M.Z.; ROCHA, R.H.; QUEIROGA, R.C.F. Produtividade de alface em função de condições de sombreamento e temperatura e luminosidade elevadas. Horticultura Brasileira, Brasília, v.23, n.2, p.189-192, abr-jun 2005.

\title{
Produtividade de alface em função de condições de sombreamento e temperatura e luminosidade elevadas
}

\author{
Francisco Bezerra Neto; Ricardo Cezar Carlos Rocha; Maria Zuleide de Negreiros; Railene Hérica C. \\ Rocha; Roberto Cleiton F. de Queiroga \\ ESAM, C.Postal. 137, 59625-900-Mossoró-RN; E-mail: bezerra@esam.br
}

\section{RESUMO}

Um experimento foi conduzido para avaliar o efeito de três tipos de telas de sombreamento em quatro alturas do nível do solo na produtividade de alface sob condições de temperatura e luminosidade elevadas de Mossoró (RN). O delineamento experimental usado foi blocos casualizados completos em esquema fatorial $3 \times 4+1$, com quatro repetições. Foram estudados três tipos de tela de sombreamento (branca, verde e preta), quatro alturas das telas em relação ao nível do solo $(20 ; 30 ; 40$ e $50 \mathrm{~cm})$, além da testemunha (cultivo a céu aberto). Foram avaliados a altura e diâmetro de planta, número de folhas por planta, produtividade, massa seca da parte aérea e taxa de crescimento da cultura. A tela branca se sobressaiu das demais no número de folhas por planta e produtividade. A máxima produtividade $\left(80,5\right.$ t.ha $\left.^{-1}\right)$ foi obtida na altura de sombreamento de 44,6 cm. Interação significativa entre os tipos de tela e alturas de sombreamento foi observada na produção de massa seca da parte aérea e na taxa de crescimento da cultura. Os maiores indicadores econômicos foram registrados na tela branca e na altura de sombreamento de $40 \mathrm{~cm}$.

Palavras-chave: Lactuca sativa, sombreamento, taxa de crescimento, indicadores econômicos.

\begin{abstract}
Lettuce yield in different shading conditions under high temperature and luminosity

The effect of three types of polyethylene screens (white, green and black) under four heights from the soil surface $(20 ; 30 ; 40$ and $50 \mathrm{~cm})$ was evaluated on the yield of lettuce (Great Lakes cv) under high temperature and luminosity conditions of Mossoró, Rio Grande do Norte State, Brazil. The control treatment consisted of the cultivation of the lettuce under open sky. The experimental design was of randomized complete blocks in a $3 \times 4+1$ factorial scheme, with four replications. Three types of shadingnet colors (white, green and black) and four heights in the bed (20; 30; 40 and $50 \mathrm{~cm}$ above soil surface) besides a control (without net) were evaluated.Plant height and diameter, number of leaves/plant, yield, shoot dry matter and plant growth rate were obtained from plants. A higher number of leaves/plant and lettuce yield was observed using the white screen. The highest lettuce yield $\left(80,5\right.$ tha $\left.^{-1}\right)$ was obtained with the screen placed $44,6 \mathrm{~cm}$ from the soil surface. There was a significant interaction between types of screen and screen heights from the soil surface on the quantity of shoot dry matter and plant growth rate. The highest economic indicators were registered with the white screen at $40 \mathrm{~cm}$ from the soil surface.
\end{abstract}

Keywords: Lactuca sativa, shading, growth rate, economic indicators.

(Recebido para publicação em 18 de novembro de 2003 e aceito em 28 de outubro de 2004)

$\mathrm{A}$ alface é uma hortaliça folhosa bastante consumida em todo o mundo e amplamente cultivada em muitos países. Sendo originária de clima temperado, sua adaptação a locais de temperatura e luminosidade elevadas tem gerado obstáculos ao seu crescimento impedindo que ela expresse todo seu potencial genético.

No Estado do Rio Grande do Norte, o cultivo desta hortaliça restringe-se a pequenas áreas, com a utilização de cultivares pouco adaptada às condições climáticas da região, o que favorece o florescimento precoce e baixa produtividade. Aliado a isto está a falta de difusão de tecnologias que melhorem o manejo desta hortaliça.

A alface é uma planta que se adapta às condições de menor fluxo de energia radiante, pelo fato da intensidade de luz afetar diretamente o crescimento e desenvolvimento das plantas. Quando se conduz uma cultura dentro de uma variação ótima de luminosidade com outros fatores favoráveis, a fotossíntese é elevada, a respiração é normal e a quantidade de matéria seca acumulada é alta. Esses benefícios à cultura podem ser viabilizados com o uso de tela de polipropileno que reduz a incidência direta dos raios solares. Nestas condições, considerando um manejo adequado de um dado cultivo, os rendimentos comerciais tendem a ser elevados.

Avaliando tipos de cobertura na atenuação da radiação solar e luminosidade com telas branca, verde e preta, Sentelhas et al. (1998) verificaram na tela branca, menor irradiação solar global $(26,6 \%)$ e menor luminosidade $(25,1 \%)$ em relação à tela preta, com irradiação solar global $(55,4 \%)$ e luminosidade (52,3\%). Ramos (1995) verificou que o sombreamento de $30 \%$ proporcionou maior altura de plantas e maior produção de massa seca de plantas de alface, tanto na fase de formação de mudas quanto na fase de campo. Queiroga (2000), avaliando o efeito de tipos de tela de sombreamento em cultivares de alface observou que a tela branca proporcionou ganho de produtividade de $27 \%$ em relação à alface sem sombreamento. Também foram observadas maiores rendas bruta e líquida e uma maior taxa de retorno com tela branca e com a cultivar Great Lakes.

Plantas de alface cultivadas sob cobertura de plásticos fotoseletivo tiveram melhor aspecto e qualidade do que aquelas cultivadas a céu aberto, apesar de seus rendimentos não diferirem significativamente entre si em qualidade e rendimento (KLEEMANN, 2004).

Miceli e D’Anna (2003), analisando o uso de diversos filmes plásticos de longa duração no cultivo de várias hortaliças em túneis, verificaram que eles 
apenas influenciaram na produtividade de algumas hortaliças.

$\mathrm{O}$ uso de telas de sombreamento em locais de temperatura e luminosidade elevadas pode contribuir para diminuir os efeitos extremos da radiação, principalmente a fotorrespiração, e proporcionar maior produtividade e qualidade das folhas para consumo (SILVA, 1998). Neste trabalho avaliou-se o efeito de três tipos de tela de sombreamento em quatro alturas do nível do solo sobre a produtividade de alface sob temperatura e luminosidade elevadas.

\section{MATERIAL E MÉTODOS}

O experimento foi conduzido em campo experimental da ESAM, entre 12/07/99 e 06/09/99, com temperatura média diurna de $29,6^{\circ} \mathrm{C}$ e insolação de 10 horas diárias. $\mathrm{O}$ solo classificado como Argissolo Vermelho Amarelo Eutrófico apresentou: pH (água 1:2,5) $=8,5 ; \mathrm{Ca}=5,4 \mathrm{cmol} \mathrm{dm}^{-3} ; \mathrm{Mg}=$ $3,2 \mathrm{cmol}_{\mathrm{c}} \mathrm{dm}^{-3} ; \mathrm{K}=2,4 \mathrm{cmol}_{\mathrm{c}} \mathrm{dm}^{-3} ; \mathrm{Na}$ $=1,3 \mathrm{cmol}_{\mathrm{c}} \mathrm{dm}^{-3} ; \mathrm{Al}=0,00 \mathrm{cmol} \mathrm{dm}^{-3} \mathrm{e}$ $\mathrm{P}=514,6 \mathrm{mg} \mathrm{dm}^{-3}$. O município de Mossoró está situado a $5^{\circ} 11^{\prime}$ de latitude Sul e $37^{\circ} 20^{\prime}$ de longitude Oeste e altitude de $18 \mathrm{~m}$. O clima da região segundo Thornthwaite, é semi-árido e, de acordo com Köppen é BSwh', seco e muito quente, com duas estações climáticas: uma seca que vai geralmente de junho a janeiro, e uma chuvosa, de fevereiro a maio.

O delineamento experimental usado foi blocos casualizados completos em esquema fatorial $3 \times 4+1$, com quatro repetições. O primeiro fator foi constituído pelos tipos de tela de sombreamento (branca, verde e preta) e o segundo pelas alturas das telas do nível do solo (20; $30 ; 40$ e $50 \mathrm{~cm})$. O tratamento adicional (testemunha) usado foi o cultivo a céu aberto. A parcela experimental foi de 1,2 $\mathrm{m}^{2}$, com 30 plantas no espaçamento de 0,20 x 0,20 m, distribuídas em 5 fileiras, considerando como úteis as 12 plantas das três fileiras centrais.

A cultivar de alface Great Lakes é do tipo repolhuda crespa, de coloração verde escura, plenamente adaptada a regiões de temperatura e luminosidade elevadas. As sementes de alface foram semeadas em 19/07/99 em copos descartáveis de $300 \mathrm{ml}$, contendo substrato comercial (mistura de húmus e vermiculita na proporção de 2:1). Foram semeadas cinco sementes por copo, à profundidade média de $0,5 \mathrm{~cm}$. Estes copos foram arranjados em seis fileiras longitudinais e colocados sob quatro estruturas de madeira, no sentido lesteoeste a 20; 30; 40 e $50 \mathrm{~cm}$ do nível do solo (altura de sombreamento). Cada estrutura teve $12,0 \mathrm{~m}^{2}$ de área sombreada, com três segmentos de $4,0 \mathrm{~m}^{2}$ na seguinte ordem: telas branca e verde, com malha formando quadrados de 2,0 $\mathrm{mm}$ de aresta, fios uniformes e secção transversal circular, e tela preta com malha aproximada de $1,5 \mathrm{~mm} \times 3,0 \mathrm{~mm}$, formando retângulos com dois tipos de fios, chatos os longitudinais e circulares os transversais. Desta forma, o sistema totalizou 12 situações distintas de microclimas sob sombreamento e uma a céu aberto que serviu de testemunha.

Durante as primeiras 72 horas, após a semeadura, a sementeira permaneceu coberta com palha de coqueiro, até o início da germinação. Foram realizados dois desbastes, sendo o primeiro aos cinco dias após o início da emergência deixando duas plantas por copo, e o segundo aos seis dias após, resultando em uma planta por copo. O sombreamento foi utilizado desde a semeadura até a véspera do transplante das mudas.

Em 30/07/99 foi realizada uma adubação foliar com um produto contendo $14,0 \% \mathrm{~N}, 4,0 \% \mathrm{P}_{2} \mathrm{O}_{5}, 6,0 \% \mathrm{~K}_{2} \mathrm{O}, 0,8 \%$ $\mathrm{S}, 1,5 \% \mathrm{Mg}, 2,0 \% \mathrm{Zn}, 1,5 \% \mathrm{Mn}, 0,1 \%$ B e $0,05 \%$ Mo, na proporção de $30 \mathrm{ml}$ $20 \mathrm{~L}^{-1}$ de água. Nos canteiros de plantio foi realizada uma adubação com esterco bovino na dosagem de $8 \mathrm{~kg} \mathrm{~m}^{-2}$. O transplantio foi realizado em 12/08/99, 24 dias após a germinação quando as mudas apresentavam de 3-4 folhas definitivas.

A irrigações foram feitas em quatro turnos: início e final da manhã, início e final da tarde, de forma a manter o teor de umidade do solo próximo à capacidade de campo. Duas capinas manuais foram realizadas de modo a evitar a concorrência com ervas daninhas. Realizouse ainda uma adubação nitrogenada em cobertura com sulfato de amônio, $20 \mathrm{~g}$ $\mathrm{m}^{-2}$ em 23/08/99 e mais duas via foliar com $14,0 \% \mathrm{~N}, 4,0 \% \mathrm{P}_{2} \mathrm{O}_{5}, 6,0 \% \mathrm{~K}_{2} \mathrm{O}$,
$0,8 \% \mathrm{~S}, 1,5 \% \mathrm{Mg}, 2,0 \% \mathrm{Zn}, 1,5 \% \mathrm{Mn}$, $0,1 \%$ B e $0,05 \%$ Mo, na proporção de $30 \mathrm{ml} 20 \mathrm{~L}^{-1}$ de água, nos dias 18 e 31/ 08/99.

A colheita foi realizada em 06/09/ 99, aos 49 dias da semeadura, quando as plantas atingiram seu máximo desenvolvimento vegetativo.

Uma amostra de quatro plantas da área útil da parcela, escolhida aleatoriamente, foi usada para a determinação dos valores no estudo de todas as características avaliadas: altura de plantas (cm), medida do nível do solo até a extremidade das folhas mais altas; diâmetro de plantas $(\mathrm{cm})$, medindo-se a distância em cm das margens opostas do disco foliar; número de folhas por planta, desprezando as folhas amarelecidas e/ou secas, partindo-se das folhas basais até a última folha aberta; produtividade, avaliada pelo peso da massa fresca da parte aérea de todas as plantas da parcela útil $\left(\mathrm{t} \mathrm{ha}^{-1}\right)$; massa seca da parte aérea $\left(\mathrm{t} \mathrm{ha} \mathrm{h}^{-1}\right)$, avaliada na amostra de quatro plantas (seca em estufa de circulação forçada de ar a $70^{\circ} \mathrm{C}$ até atingir peso constante) e taxa de crescimento da cultura $\left(\mathrm{g} \cdot \mathrm{cm}^{-2} \cdot \mathrm{dia}^{-1}\right)$, determinada por meio de duas amostragens da massa seca da parte aérea, sendo uma por ocasião do transplantio, e outra quando as plantas apresentavam-se no ponto de colheita (em máximo desenvolvimento, mas ainda com folhas tenras e sem indício de florescimento), conforme expressão a seguir:

$\mathrm{T}_{\mathrm{cc}}=\mathrm{M}_{\mathrm{s} 2}-\mathrm{M}_{\mathrm{s} 1} / \mathrm{E}_{\mathrm{c}} * \mathrm{P}$, onde $\mathrm{T}_{\mathrm{cc}}=$ taxa de crescimento da cultura $\left(\mathrm{g} \mathrm{cm}^{-2}\right.$ $\left.\operatorname{dia}^{-1}\right), M_{\mathrm{s} 2}=$ massa seca na segunda amostragem $(\mathrm{g}), \mathrm{M}_{\mathrm{s} 1}=$ massa seca na primeira amostragem $(\mathrm{g}), \mathrm{E}_{\mathrm{c}}=$ espaçamento da cultura $\left(\mathrm{cm}^{2}\right)$ e $\mathrm{P}=$ período entre amostragens (dias).

A análise de variância foi utilizada na obtenção do efeito dos tipos de tela e altura do sombreamento sobre as características coletadas. O teste de Tukey foi usado para comparar as diferenças entre os efeitos médios dos tipos de tela de sombreamento e a análise de regressão foi usada para ajustar as curvas de repostas para as características avaliadas em função das alturas de tela de sombreamento (JANDEL SCIENTIFIC, 1991).

A análise econômica do experimento foi realizada utilizando-se indicado- 
res de rendas bruta e líquida e taxa de retorno. A renda bruta foi obtida multiplicando-se a produtividade de cada tratamento pelo valor do produto obtido, que foi de $\mathrm{R} \$ 0,50$ por quilo, pago ao produtor no mês de outubro de 1999. A renda líquida foi obtida subtraindo-se da renda bruta, os custos de produção, provenientes de insumos e serviços. Estes custos foram calculados para cada tratamento baseado nos coeficientes de custos de insumos e serviços utilizados em 1 hectare de alface em nível experimental. Foram considerados os preços de insumos e serviços vigentes no mês de outubro de 1999, na cidade de Mossoró. A taxa de retorno por real investido foi obtida por meio da relação entre a renda bruta e o custo de produção de cada tratamento.

\section{RESULTADOS E DISCUSSÃO}

Não houve interação significativa entre os tipos de tela e altura de sombreamento para as variáveis altura e diâmetro das plantas, número de folhas por planta e produtividade de alface (Tabela 1). Também, não foi observado efeito significativo destes fatores isolados na altura e diâmetro das plantas. Estes resultados discordam, em parte, dos obtidos por Queiroga (2001), que encontrou diferenças entre os tipos de tela de sombreamento na altura de plantas de alface.

Nenhuma diferença significativa entre os tipos de telas de sombreamento e a testemunha (alface cultivada a céu aberto) foi observada nestas características (Tabela 1).

Tabela 1. Efeito de diferentes tipos de tela de sombreamento sobre a altura e diâmetro das plantas, número de folhas por planta, produtividade estimada e incremento de produtividade em relação ao controle (sem tela), em alface 'Great Lakes' na região de Mossoró. ESAM, 1999, Mossoró.

\begin{tabular}{llllcc}
\hline $\begin{array}{l}\text { Tipos de } \\
\text { tela }\end{array}$ & $\begin{array}{c}\text { Altura de } \\
\text { plantas } \\
(\mathbf{c m})^{+}\end{array}$ & $\begin{array}{c}\text { Diâmetro de } \\
\text { plantas } \mathbf{( c m )}\end{array}$ & $\begin{array}{c}\text { Folhas por } \\
\left.\text { planta (N }{ }^{\circ}\right)\end{array}$ & $\begin{array}{c}\text { Produtividade } \\
\text { de alface } \\
\text { (t.ha-1) }\end{array}$ & $\begin{array}{c}\text { Incremento de } \\
\text { produtividade } \\
\text { sobre a } \\
\text { testemunha (\%) }\end{array}$ \\
\hline Branca & $26,62 \mathrm{a}$ & $34,99 \mathrm{a}$ & $18,28 \mathrm{a}$ & $83,64 \mathrm{~A}$ & 25,45 \\
Verde & $26,05 \mathrm{a}$ & $32,04 \mathrm{a}$ & $17,23 \mathrm{ab}$ & $78,34 \mathrm{Ab}$ & 17,50 \\
Preta & $25,76 \mathrm{a}$ & $32,71 \mathrm{a}$ & $16,05 \mathrm{~b}$ & $72,72 \mathrm{~B}$ & 9,07 \\
Sem tela & 24,40 & 36,11 & 18,23 & $66,67{ }^{*}$ & \\
\hline
\end{tabular}

${ }^{+}$Médias seguidas pela mesma letra na coluna não diferem significativamente entre si pelo teste Tukey ao nível de $5 \%$ de probabilidade.

*Significativamente diferente da média dos três tipos de tela.

As equações de regressão para estas características foram ajustadas em função das alturas de sombreamento (Tabela 2). Comportamento quadrático foi registrado para as alturas de plantas, com valor máximo de $26,6 \mathrm{~cm}$ obtido na altura de sombreamento de $37,5 \mathrm{~cm}$. Por outro lado, registrou-se comportamento decrescente no diâmetro de plantas com o aumento das alturas de sombreamento, atingindo a altura máxima de $20 \mathrm{~cm}$.

Diferenças significativas entre os tipos de tela de sombreamento foram observadas no número de folhas por planta e na produtividade da alface, com a tela de cor branca destacando-se das demais (Tabela 1). Esta superioridade da tela de cor branca nestas características se deve ao maior fluxo de fótons no ambiente, conseqüentemente maior fotossíntese e produção de fotossintatos. Isto confirma em parte, a afirmativa de Edmond et al. (1967), de que numa cultura, quando conduzida dentro de variação ótima de luminosidade com outros fatores favoráveis, a fotossíntese é elevada e a quantidade de carboidratos utilizados para o crescimento e desenvolvimento da planta é alta.

Diferenças significativas entre os tipos de telas de sombreamento e a testemunha foram observadas apenas na produtividade da alface. Foram registrados ganhos de produtividade na tela branca de $25,45 \%$; verde de $17,50 \%$ e preta de $9,07 \%$, em relação à testemunha, sem tela (Tabela 1). Estes dados corroboram com aqueles obtidos por Queiroga (2001).

Equações de regressão foram ajustadas para estas variáveis em função das alturas de sombreamento (Tabela 2). Foi observada redução no número de folhas por planta em função do aumento da altura de sombreamento, atingido o máximo na altura de $20 \mathrm{~cm}$. Na produtividade de alface foi registrado um comportamento quadrático em função das alturas de sombreamento, com valor máximo de $80,5 \mathrm{t} \mathrm{ha}^{-1}$ para altura de $44,6 \mathrm{~cm}$.

Tabela 2. Funções de respostas ajustadas em relação às alturas de sombreamento para a altura e diâmetro de plantas, número de folhas por planta, produtividade, massa seca da parte aérea e taxa de crescimento em alface 'Great Lakes', na região de Mossoró. ESAM, 1999, Mossoró.

\begin{tabular}{llc}
\hline Características avaliadas & Funções de resposta ajustadas & $\mathbf{R}^{\mathbf{2}}$ \\
\hline Altura de plantas & $\mathrm{Y}=21,714+0,260 \mathrm{X}-0,003$ X2 & 0,96 \\
Diâmetro de plantas & $\mathrm{Y}=32,334+777,076 /$ X2 & 0,98 \\
Número de folhas/planta & $\mathrm{Y}=17,6725-0,0003 \mathrm{X} 2$ & 0,95 \\
Produtividade & $\mathrm{Y}=59,63+0,937 \mathrm{X}-0,010 \mathrm{X} 2$ & 0,99 \\
Massa seca de folha na tela branca & Nenhuma função ajustada & 0,99 \\
Massa seca de folha na tela verde & $\mathrm{Y}=-0,6265+0,2471 \mathrm{X}-0,0036$ X2 & 0,89 \\
Massa seca de folha na tela preta & $\mathrm{Y}=2,72+5,30 / \mathrm{X}$ & 0,99 \\
Taxa de crescimento da cultura na tela branca & Nenhuma função ajustada & 0,94 \\
Taxa de crescimento da cultura na tela verde & $\mathrm{Y}=-5,9035+2,8713 \mathrm{X}-0,0416 \mathrm{X} 2$ & \\
Taxa de crescimento da cultura na tela preta & $\mathrm{Y}=32,42+67,62 / \mathrm{X}$ & \\
\hline
\end{tabular}


Tabela 3. Indicadores econômicos de renda bruta (RB), renda liquida (RL), taxa de retorno em reais (TR) e incremento da renda bruta e taxa de retorno de diferentes tipos de tela de sombreamento em relação ao controle (sem tela), em alface 'Great Lakes', na região de Mossoró. ESAM, 1999, Mossoró.

\begin{tabular}{|c|c|c|c|c|}
\hline Tipos de telas & Renda bruta & Renda liquida & Taxa de retorno & $\begin{array}{l}\text { Incremento da } \\
\text { RB e TR sobre } \\
\text { a testemunha }\end{array}$ \\
\hline Branca & $41.820,00$ & $25.144,93$ & 2,51 & 25,5 \\
\hline Verde & $39.170,00$ & $22.494,93$ & 2,35 & 17,6 \\
\hline Preto & $36.360,00$ & $19.684,93$ & 2,18 & 9,0 \\
\hline Sem tela & $33.335,00$ & $16.659,93$ & 2,00 & \\
\hline \multicolumn{5}{|l|}{ Alturas de Telas } \\
\hline $20 \mathrm{~cm}$ & $37.055,00$ & $20.379,93$ & 2,22 & \\
\hline $30 \mathrm{~cm}$ & $39.100,00$ & $22.424,93$ & 2,34 & \\
\hline $40 \mathrm{~cm}$ & $40.190,00$ & $23.514,93$ & 2,41 & \\
\hline $50 \mathrm{~cm}$ & $40.120,00$ & $23.444,93$ & 2,41 & \\
\hline
\end{tabular}

Interação significativa entre os tipos de tela e alturas de sombreamento foi observada para massa seca da parte aérea e na taxa de crescimento da cultura. Desdobrando-se esta interação, registraram-se diferentes comportamentos das alturas de sombreamento dentro de cada tipo de tela (Tabela 2). Sob a tela branca, nenhuma função resposta foi obtida para estas variáveis. Para a tela de cor verde foi observado comportamento quadrático, com valores máximos de massa seca e taxa de crescimento da cultura de 3,64 t ha ${ }^{-1}$ e 43,6 g.cm dia $^{-1}$, respectivamente na altura de sombreamento de $34,5 \mathrm{~cm}$. Sob a tela preta, uma redução nestas variáveis foi registrada, com valores máximos obtidos na altura de $20 \mathrm{~cm}$. Estes resultados se devem, à quantidade de radiação filtrada pelas telas de sombreamento nas diferentes alturas, com a tela branca deixando passar mais radiação, seguida pela verde e preta.

Observa-se pelos indicadores econômicos melhores resultados no tipo de tela branca, com valores de $\mathrm{R} \$$ $41.820,00$, para a renda bruta, de $\mathrm{R} \$$ 25.144,93 para renda líquida e 2,51 para a taxa de retorno (Tabela 3). Quando se comparou estes indicadores nos diversos tipos de telas com a testemunha a céu aberto, verificou-se, que a tela branca teve incremento de $25 \%$. Por outro lado, as alturas de sombreamento que registraram os maiores indicadores econômicos foram $40 \mathrm{~cm}$, com rendas bruta e líquida e taxa de retorno de $\mathrm{R} \$$ 40.190,00 e R $\$ 23.514,93$ e 2,41, respectivamente, e $50 \mathrm{~cm}$ com taxa de retorno de 2,41 (Tabela 3). Estes resultados superaram normalmente os obtidos pelos produtores de alface da região que auferem valores de 1,60.

De modo geral pelos resultados obtidos, infere-se que os efeitos negativos de temperatura e luminosidade elevadas na produtividade da alface nas condições do semi-árido nordestino podem ser minimizados de forma significativa quando se utiliza tela de sombreamento branca a uma altura a partir de $40 \mathrm{~cm}$.

\section{LITERATURA CITADA}

EDMOND, J.B.; SENN, T.L.; ANDREWS, E.S. Princípios de horticultura. México: Continental, 1967. p.119-134.

JANDEL SCIENTIFIC. Tablecurve user's manual. Corte Madera, CA: Jandel Scientific, 1991. 280 p.

KLEEMANN, M. Effect of photoselective plastics on the quality of lettuce. Acta Horticulturae, Leuven, v.633, n.1, p.173-179, 2004.

MICELI, A.; D'ANNA, F. Effect of different plastic cover films on the production of some vegetable crops. Acta Horticulturae, Leuven, v. 614, n.1, p.421-425, 2003.

QUEIROGA, R.C.F. Produção de alface em função de cultivares e tipos de tela de sombreamento nas condições de Mossoró - RN. 2000. $28 \mathrm{f}$. (Tese mestrado) - ESAM, Mossoró.

RAMOS, J.E.L. Sombreamento e tipos de recipientes na formação de mudas e produção em alface. 1995. 53 f. (Tese mestrado) - ESAM, Mossoró.

SENTELHAS, P.C.;VILLA NOVA, N.A .; ANGELOCCI, L.R. Efeito de diferentes tipos de cobertura, em mini-estufas, na atenuação da radiação solar e da luminosidade. Revista Brasileira de Agrometeorologia, v.6, n.1, p.479-481, 1998.

SILVA, V.F. Cultivares de alface em diferentes espaçamentos sob temperatura e luminosidade elevadas. 1998. 25 f. (Tese mestrado) - ESAM, Mossoró. 